removal of DNA-containing immune complexes from blood using composite sorbent. Patent RU2441674 (2010) [in Russian].

Disclosure of Interest: None declared

DOI: 10.1136/annrheumdis-2017-eular.2593

\section{FRI0147 ANTI-MÜLLERIAN HORMONE LEVELS IN FEMALE RHEUMATOID ARTHRITIS PATIENTS TRYING TO CONCEIVE - THE ROLE OF OVARIAN FUNCTION IN TIME TO PREGNANCY IN A NATIONWIDE COHORT STUDY}

J. Brouwer $^{1,2}$, J.S. Laven ${ }^{1}$, J.M. Hazes ${ }^{2}$, J.A. Visser ${ }^{3}$, R.J. Dolhain ${ }^{2}$. ${ }^{1}$ Division of Reproductive Medicine - Department of Obstetrics \& Gynaecology; ${ }^{2}$ Department of Rheumatology; ${ }^{3}$ Department of Internal Medicine, Erasmus MC University Medical Center Rotterdam, Rotterdam, Netherlands

Background: Subfertility, a time to pregnancy (TTP) $>12$ months, is present in $40 \%$ of women with rheumatoid arthritis (RA) actively trying to conceive. ${ }^{1}$ Since RA patients appear to reach menopause at a younger age $^{2}$, the reduced fertility may be caused by a lower ovarian reserve (OR). Serum anti-Müllerian hormone $(\mathrm{AMH})$ levels are currently the most reliable way to measure the OR.

Objectives: Our objective was to study preconception $\mathrm{AMH}$ levels and their association with TTP in women with RA

Methods: A post-hoc analysis was performed in patients of the Pregnancyinduced Amelioration of RA (PARA) cohort who were visited preconceptionally. Serum AMH levels were measured using the pico AMH ELISA assay (Ansh Labs, Texas, USA), and compared to converted ${ }^{3} \mathrm{AMH}$ values from a cohort of 554 healthy adult controls ${ }^{4}$.

Results: Preconception serum was available in 209 women aged $32.1 \pm 3.9$ years, of whom $45 \%$ were subfertile. The median AMH level was $2.5 \mathrm{ug} / \mathrm{L}$ (IQR 1.5-4.6). AMH levels were significantly lower compared to healthy controls $(p<0.001)$, with $17.2 \%(95 \% \mathrm{Cl} 10.7-23.8 \%)$ of patients having levels below the age-specific 10th percentile.

Log-transformed AMH levels were negatively associated with age $(-0.070(95 \%$ $\mathrm{Cl}-0.11 ;-0.031), \mathrm{p}=0.001)$, and with the presence of anti-citrullinated protein antibodies (ACPA) $(-0.38(95 \% \mathrm{Cl}-0.71 ;-0.056), \mathrm{p}=0.022)$. The associations remained significant in the multivariable analyses. $\mathrm{AMH}$ levels showed no significant association with TTP (HR 1.09 (95\% Cl 0.94;1.27), $\mathrm{p}=0.26)$.

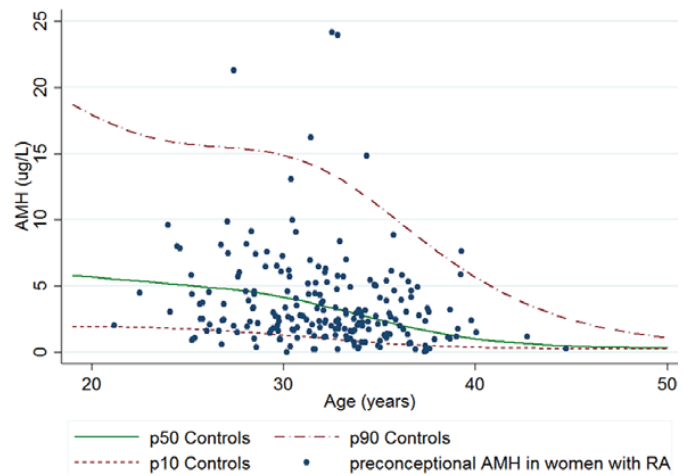

Conclusions: Women with RA have lower AMH levels than healthy controls. Reduced AMH levels were more pronounced in ACPA positive patients, suggesting that the OR may be compromised more strongly in patients with a more severe disease. However, since preconception AMH levels were not associated with TTP, the reduced levels do not explain the reduced fertility in women with RA.

\section{References:}

[1] Brouwer J, Hazes JM, Laven JS, Dolhain RJ. Fertility in women with rheumatoid arthritis: influence of disease activity and medication. Ann Rheum Dis 2015;74:1836-41.

[2] Del Junco DJ, Annegers JF, Coulam CB, Luthra HS. The relationship between rheumatoid arthritis and reproductive function. Br J Rheumatol 1989;28 Suppl 1:33; discussion 42-5

[3] Su HI, Sammel MD, Homer MV, Bui K, Haunschild C, Stanczyk FZ. Comparability of antimullerian hormone levels among commercially available immunoassays. Fertil Steril 2014;101:1766-72 e1.

[4] Lie Fong S, Visser JA, Welt CK, et al. Serum anti-mullerian hormone levels in healthy females: a nomogram ranging from infancy to adulthood. J Clin Endocrinol Metab 2012;97:4650-5.

Acknowledgements: This study was funded by the Dutch Arthritis Foundation (Reumafonds).

The pico AMH assays were generously provided by Ansh Labs (Houston, Texas, USA).

Furthermore, we would like to thank all patients and rheumatologists who contributed to the PARA study, as well as all researchers and laboratory workers who worked on this project.

Disclosure of Interest: J. Brouwer: None declared, J. Laven: None declared, J. Hazes: None declared, J. Visser: None declared, R. Dolhain Grant/research support from: unrestricted research grant by UCB Pharma BV
DOI: 10.1136/annrheumdis-2017-eular.2105

\section{FRI0148 THE EFFECT OF TNF INHIBITORS, METHOTREXATE (MTX) AND THE OTHER DMARDS THERAPIES ON DIABETIC CONTROL IN PATIENTS WITH RHEUMATOID ARTHRITIS (RA): TREATMENT WITH MTX ALONE IMPROVED DIABETES CONTROL MORE THAN TNF INHIBITORS PLUS MTX}

K. Fujioka, M. Tangiku, M. Fuwa, I. Mori, T. Ishizuka. Center of General Internal Medicine and Rheumatology, Gifu Municipal Hospital, Gifu City, Japan

Background: It has been shown that inflammation directly influences insulin and glucose metabolism through cytokines such as TNF $\alpha$ and IL-6. It has also been reported that certain RA drugs such as TNF inhibitors, hydroxychloroquine, and MTX were associated with lower diabetes risk among people with RA, but it is still clinically unknown. On the other hand, it has been shown that MTX is involved in activation of intracellular AMP-kinase and promotes glucose uptake in skeletal muscle (Diabetes, 2015).

Objectives: We examined medical records of patients with new RA patients complicated with glucose intolerance to measure in $\mathrm{HbA1c}$, body weight, and DAS28-ESR for 6 and 12 months treated with TNF inhibitors, MTX, and the other DMARDs.

Methods: Newly registered 20 RA patients complicated with glucose intolerance ( $\mathrm{HbA1c}>5.6 \%)$ at our hospital from May 2013 to December 2015, have treated with as follows; Treatment with infliximab (1 case), golimumab ( 3 cases), and etanercept ( 2 cases) in combination with 4-12mg/week of MTX (group A: 6 cases, TNF inhibitors + MTX), MTX (4-10 mg/week) alone (group B: 8 cases MTX alone). The other DMARDs (group C: 6 cases, the other DMARDs including bucillamine $(B C L)+$ salazosulfapyridine (SASP) + tacrolimus (TAC); 1case, BCL+SASP; 1 case, $\mathrm{BCL}$ alone; 2 cases and SASP alone; 2 cases) had been registered. We have compared the changes of $\mathrm{HbA} 1 \mathrm{c}$ levels, body weight, DAS 28-ESR from the beginning of the treatments and 6 and 12 months later. RA patients treated with glucocorticoid were excluded. Diabetic treatment were diet and exercise in all cases, but metformin (500 mg) and DPP4 inhibitor were used in 4 cases (Group A and C). However, each patient in Group B did not use antidiabetic agents. We analyzed these results with paired and unpaired $t$ test using JMP12.2.0.

Results: These registered RA patients with female were $60.0 \%$. The mean age were $62.1,53.5$ and 63.8 for group $A, B$, and $C$, respectively. There were significant changes in DAS28-ESR after treatment for 6 months in group $A$ and $B$, respectively $(p<0.01$ in group $A$ and $p<0.05$ in group $B)$.

Groups A and B showed significant improvement of DAS 28-ESR after treatment with 12 months $(P<0.0001$ in group $A, p<0.01$ in group $B)$, but no significant difference of DAS28-ESR in group $C$ was observed. The mean reduction in $\mathrm{HbA} 1 \mathrm{C}$ showed a significantly decreases only in the group $B(P<0.01)$. There were no significant differences in body weight between the each group, but slightly an increase in body weight was observed in group B. There were no significant correlations between body weight and DAS28-ESR and its changes.

Conclusions: In this study, MTX was thought to contribute not only to suppress chronic inflammation but also to improve the glucose tolerance as compared with TNF inhibitors plus MTX and the other DMARDs. Further studies concerns about the interrelationship between glucose tolerance and RA treatments may require. References:

[1] Sergej Pirkmajer, et al. Diabetes 2015;64:360-369.

[2] Laura R. Rekedal, et al. Arthritis Rheum.2010;62(12):3569-3573.

[3] Daniel H. Solomon, et al. JAMA.2011;305(24):2525-2531.

Disclosure of Interest: None declared

DOI: 10.1136/annrheumdis-2017-eular.4914

\section{FRI0149 DOES THYROXIN SUBSTITUTION PREDICT NON-RESPONSE TO METHOTREXATE IN EARLY RA?}

K. Waldenlind ${ }^{1}$, S. Saevarsdottir ${ }^{1}$, C. Bengtsson ${ }^{2}$, J. Askling ${ }^{1} .{ }^{1}$ Rheumatology Unit, Department of Medicine, Solna, Karolinska Institute; ${ }^{2}$ Institute of Environmental Medicine, Karolinska Institute, Stockholm, Sweden

Background: Response to treatment varies widely between RA-patients. Our means to predict disease course and treatment response is limited, leading to substantial over- as well as under- treatment. Whereas female gender and smoking have been identified as predictors of non-response, the impact of autoimmune co-morbidities remains largely unknown. Autoimmune thyroid disease (AITD) is one of the most frequent autoimmune diseases in the population. AITD is more prevalent in RA-patients and has also been identified as a risk factor for RA. AITD can be readily identified via thyroxin substitution. We aimed at assessing the impact of prevalent AITD in relation to 3- and 6-month EULAR response to methotrexate in early RA.

Objectives: To investigate whether thyroxin substitution impacts response to methotrexate as the first-line therapy in RA.

Methods: We identified patients with incident RA (symptom duration $<1$ year), included in the Swedish Rheumatology Quality Register, July 2006 through $2015(n=7009)$. All patients starting treatment with methotrexate and who had a follow-up visit at 3 months $(n=4364)$ and/or at 6 months $(n=3148)$ were included. Prevalent AITD was defined as prescription of thyroxin substitution before RAdiagnosis $(n=347)$, based on linkage to the Swedish Prescribed Drug register, 
and excluding participants with prescriptions for iodine-containing drugs or history of thyroid cancer (e.g. non-autoimmune cause of thyroxin use). We used a casecontrol design with thyroxin substitution as exposure, cases defined as EULAR DAS28 3- and 6-month non-responders, and controls defined as moderate/good responders at these time-points. Odds Ratios (OR) were calculated adjusted for sex, age, and $\mathrm{HAQ}$.

Results: At 3 months, the proportion of thyroxin users did not differ between responders and non-responders $12 \%$ vs. $11 \%$, (OR non-response $=1.1,95 \% \mathrm{Cl}$ $0.9-1.4$ ). At 6 months, the corresponding figures were $13 \%$ vs. $11 \%$, respectively, (OR non-response $=1.3,95 \% \mathrm{Cl} 1.0-1.7$ ). However, a significant difference was observed in RF and/or ACPA positive patients at 6 months, where $15 \%$ of non-responders and $10 \%$ of responders used thyroxin (OR non-response $=1.6$, $95 \% \mathrm{Cl}$ 1.1-2.1), while no such difference was observed for seronegative RA. When stratified for gender, thyroxin substitution was significantly associated with non-response in men but not in women.

Table 1. Relative risk of prevalent AITD before RA-diagnosis in non-responders compared to moderate and good responders according to EULAR response criteria, at the 6 month follow-up visit among 3148 RA-patients starting methotrexate as first ever DMARD

\begin{tabular}{lcc}
\hline & $\begin{array}{c}\text { No of AITD in non-responders (718)/ } \\
\text { moderate and good responders }(887+1543)\end{array}$ & Adj. OR (95\% Cl) \\
\hline $\begin{array}{l}\text { Overall } \\
\text { Sex }\end{array}$ & $93(13 \%) / 254(11 \%)$ & $1.28(0.98-1.66)$ \\
$\quad$ Women & $81(16 \%) / 231(14 \%)$ & $1.19(0.89-1.57)$ \\
$\quad$ Men & $12(5.6 \%) / 23(2.8 \%)$ & $2.20(1.05-4.60)$ \\
Serostatus & $73(15 \%) / 163(10 \%)$ & $1.57(1.14-2.14)$ \\
$\quad$ RF and/or ACPA positive & $20(8.9 \%) / 80(11 \%)$ & $0.82(0.48-1.42)$ \\
$\quad$ RF and ACPA Negative & $0 / 11$ & NA \\
\hline Serostatus unspecified & &
\end{tabular}

Values are the number. RA = rheumatoid arthritis; AITD = autoimmune thyroid disease; OR = odds ratio; $95 \% \mathrm{Cl}=95 \%$ confidence interval.

Conclusions: This large real-life study of response to methotrexate in early RA suggests that AITD, measured as thyroxin replacement therapy, may be linked to treatment response in seropositive patients (and among males). Exploratory by nature, these findings call for replication.

Disclosure of Interest: K. Waldenlind: None declared, S. Saevarsdottir: None declared, C. Bengtsson: None declared, J. Askling Grant/research support from: Abbvie, Pfizer, Lilly, Samsung, MSD, UCB, Roche, Janssen

DOI: 10.1136/annrheumdis-2017-eular.3725

\section{FRI0150 EPIDEMIOLOGICAL DESCRIPTION OF PSYCHOLOGICAL, SEXUAL AND SLEEP DISORDERS IN PATIENTS WITH RHEUMATOID ARTHRITIS AND CORRELATION BETWEEN THEM AND DISEASE ACTIVITY}

L. Villarreal ${ }^{1}$, S. Henao ${ }^{2}$, D. Buitrago-Garcia ${ }^{3}$, P. Santos-Moreno ${ }^{4} .{ }^{1}$ Psychology and processes; ${ }^{2}$ Patient service; ${ }^{3}$ Epidemiology; ${ }^{4}$ Rheumatology, Biomab, Center for Rheumatoid Arthritis, Bogota, Bogota, Colombia

Background: Rheumatoid arthritis (RA) is the prevalent autoimmune inflammatory arthritis found in adults, with the worldwide prevalence ranging from $0.4 \%$ to $1.3 \%$. Psychological disorders can be underestimated in this population; on the other hand studies had shown that the daily experience with RA can lead to sleep, psychological and sleep disorders.

Objectives: To characterize a population with RA and to describe the psychological, sexual and sleep disorders in a specialized rheumatology center in Bogotá Colombia.

Methods: We perform a cross-sectional study of patients attending to our psychology consultation the information was collected through semi-structured interviews, also using classificatory criteria of pathologies described in CIE 10 diagnostic manual, applying descriptive epidemiology for continuous variables, measure of central tendency and dispersion for qualitative and categorical variables through percentages and averages.

Results: We included 1398 patients attending to our psychology consultation. Mean age was 55 years $\pm 8 ; 80 \%$ were female and $20 \%$ male. Mean DAS28 was $2.6 \pm 1.3$, mean $\mathrm{HAQ}$ was 1.6 \pm 1.6 ; patients had the disease for an average of 12 years $+8 ; 41 \%$ of patients had comorbidities associated with non-autoimmune disease, $14 \%$ comorbidities related to autoimmune disease; $35 \%$ of our patients did not report other comorbidities. Most of patients were married $60 \%$, followed by divorced $19 \%$, single $14 \%$ and widowed $7 \%$. Regarding occupation $33 \%$ were employees, $25 \%$ were housekeepers or retired due to age, $12 \%$ were retired due to disabilities, and $3 \%$ unemployed. Of the total population $45 \%$ had elementary school, $32 \%$ high school, $8 \%$ college education, $7 \%$ graduate education and $7 \%$ were illiterate. $17 \%$ of patients lived alone. Regarding psychological factors $25 \%$ had any mood disorders, $13 \%$ sleep disorders, $12 \%$ somatomorphic disorders, $6 \%$ sexual dysfunction, $2 \%$ dementia, $4 \%$ eating disorders and $38 \%$ reported no to have any of the above. Concerning sexual disorders, $38 \%$ reported no to have any sexual activity, $32 \%$ reported to have a satisfactory sexual life, $11 \%$ dyspareunia, $9 \%$ had an unsatisfactory sexual life, $5 \%$ loss of desire, $3 \%$ premature ejaculation and $2 \%$ orgasmic decrease. When the psychologist asked about sleep disorders $69 \%$ reported no to have any, $25 \%$ primary insomnia, $1 \%$ hypersomnia, $3 \%$ OSAS and $2 \%$ alterations on the circadian rhythm. There was a statistical association between psychological and sexual disorders, sleep and sexual disorders and, psychological and sleep disorders. Disease activity was associated only with sleep disorders.

Conclusions: Not only DMARDs disease management should be a priority for RA patients, factors such as sleep, sexual and psychological are important because one third of patients have it; on the other hand there is a interdependence between them and disease activity. Thus, it is important to have a multidisciplinary care team for the patient with RA, including a psychologist that can manage this kind of conditions and if necessary refer to a psychiatrist consultation.

Disclosure of Interest: None declared

DOI: 10.1136/annrheumdis-2017-eular.5622

\section{FRI0151 DISEASE COURSE IN SERONEGATIVE RA PATIENTS CLASSIFIED ACCORDING TO THE 2010 ACR/EULAR CRITERIA}

L.B. Nordberg ${ }^{1}$, S. Lillegraven ${ }^{1}$, A.-B. Aga ${ }^{1}$, I.C. Olsen ${ }^{1}$, E. Lie ${ }^{1}$, H.B. Hammer ${ }^{1}$, T. Uhlig ${ }^{1}$, D. van der Heijde ${ }^{2}$, T.K. Kvien ${ }^{1}$, E.A. Haavardsholm ${ }^{1}$ on behalf of the ARCTIC study group. ${ }^{1}$ Diakonhjemmet Hospital, oslo, Norway; ${ }^{2}$ Leiden University medical center, Leiden, Netherlands

Background: The development of the 2010 classification criteria for rheumatoid arthritis (RA) has led to a redefinition of the patient population, including classification of seropositive versus seronegative patients. In our recently published study of DMARD naîve early RA patients fulfilling the 2010 ACR/EULAR criteria, we found seronegative patients to have markedly higher disease activity at time of diagnosis, compared to seropositive patients.[1] There is very limited information about the disease course of seronegative patients classified according to the new criteria.

Objectives: Our aim was to examine the disease course of seronegative early RA patients fulfilling the 2010 ACR/EULAR criteria.

Methods: In the treat-to-target ARCTIC trial, DMARD-naive RA patients classified according to the 2010 EULAR/ACR criteria were randomised 1:1 to follow-up with or without ultrasound. Patients in both arms were treated according to the same DMARD escalation strategy. Patients were assessed at 13 visits during two years of follow-up.[2] We stratified the patients as seropositive (rheumatoid factor $(\mathrm{RF})+$, anti-citrullinated peptide antibody (ACPA)+, or both) or seronegative (RFand ACPA-). At 24-month follow-up, measures of disease activity were compared across the groups using independent samples t-test, Mann-Whitney $\mathrm{U}$ test or chi square test as appropriate.

Results: A total of 230 patients were included, the mean (SD) age was 51.4 (13.7) years and $61.3 \%$ were female; 34 patients $(14.8 \%)$ were seronegative. The mean age (SD) was $55.4(2.7) / 50.8(0.9)$ years $(\mathrm{p}=0.07)$, mean (SD) disease duration was $7.7(6.8) / 7.0(5.1)$ months $(p=0.46)$, and $56 / 62 \%$ were females $(p=0.48)$ in the seronegative/seropositive groups. At 24 -month follow-up, measures of disease activity were similar between groups (table). There was a tendency towards more radiographic damage in the seronegative patients. Seronegative patients had a significantly greater reduction (0-24 months) in disease activity measures in terms of DAS, number of swollen joints, physician global and ultrasonography scores (table).

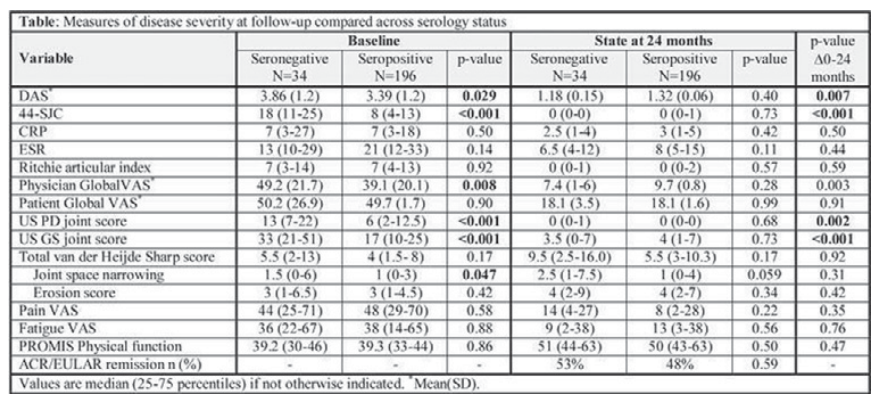

Conclusions: In this study of early RA patients, seronegative patients had more inflammatory activity at baseline and a tendency to more radiographic damage, but disease activity after two years of treat-to-target therapy was similar to the seropositive patients. Our findings suggest that seronegative patients classified according to the new criteria respond to modern treatment strategies, with similar rates of patients reaching remission compared to seropositive patients.

References:

[1] Nordberg LB et al. Annals of the rheumatic diseases 2017;76:341-345.

[2] Haavardsholm EA et al., BMJ 2016;354:i4205.

Disclosure of Interest: L. Nordberg: None declared, S. Lillegraven: None declared, A.-B. Aga: None declared, I. Olsen: None declared, E. Lie: None declared, H. Hammer Consultant for: AbbVie, Pfizer, BMS, Roche, UCB, T. Uhlig: None declared, D. van der Heijde: None declared, T. Kvien: None declared, E. Haavardsholm Grant/research support from: Pfizer, MSD, UCB, AbbVie, Roche DOI: 10.1136/annrheumdis-2017-eular.4967 